\title{
The Comparative Impacts of Using Lexical Glossing and Inferencing Strategies on Students' Reading Comprehension
}

Juliana*

Potensi Utama University, Medan, Indonesia

Corresponding Author: Juliana, E-mail: juliana.ssmsi@gmail.com

\section{ARTICLE INFO}

Article history

Received: November 18, 2017

Accepted: December 22, 2017

Published: February 28, 2018

Volume: 9 Issue: 1

Advance access: January 2018

Conflicts of interest: None

Funding: None

\section{Key words:}

Glossing and Inferencing Strategies,

Reading Comprehension,

Comparative Study

\begin{abstract}
The study compared the use of the lexical glossing and inferencing strategies that impact toward the students' reading comprehension. The objective of the study was to find out the effective strategy to use for enhancing the students' reading comprehension. The population of the study was 40 Informatics Systems students of Potensi Utama University. The data collection was used written test by comparing the scores results after giving the treatment. The written test was conducted to identify students' reading comprehension performance toward the use of lexical glossing and inferencing strategies. The data was analyzed applying an experimental research design. There were two tests in this study before and after treatment. Before treatment without using the strategies, the first test was applied to first group and second group. After treatment with using the strategies, the second test was applied to the first and second group. The first group was taught using lexical glossing strategy, while the second group was treated using lexical inferencing strategies. The test resulted that the students in the second group using lexical inferencing strategies could guess the unfamiliar word meaning correctly that impact toward the students' reading comprehension. While the students in the first group using the lexical glossing strategy make erroneous guesses about unfamiliar word meaning that impact on the students' reading comprehension. Therefore, it can be concluded that lexical inferencing strategy was recommended to teach to enhance the students' reading comprehension.
\end{abstract}

\section{INTRODUCTION}

To achieve the reading comprehension, a reader must have the ability, experience and knowledge to understand the text meaning. One of the important knowledge in reading comprehension is vocabulary knowledge. As Schmitt states (2010:4) that vocabulary knowledge helps to communicate between the writer and the reader to get the similar understanding of the text. The understanding of the text can be achieved by mastering the vocabulary knowledge. The more much the vocabulary mastery have, the more the text well comprehend. The vocabulary mastery and reading are clearly related for the understanding of words meaning and their use that contribute to reading comprehension. Stoller \& Grabe (1993:23) states that vocabulary mastery is essential element in reading comprehension. By mastering vocabulary is automotically helping the reading comprehension. In short, the reader with the vocabulary mastery can be able to understand the text well.

To become a good reader, the students must not only have the vocabulary mastery, but also need to learn the way to understand the unfamiliar word meaning during the reading process. The appropriate way to understand unfamiliar word meaning as long as they read can be used to understand the text meaning easily. One of the alternative ways to use are as the strategy to understand the unfamiliar word meaning in the text like vocabulary knowledge background. Students should be able to develop this vocabulary knowledge and also use the effective strategy to help their understanding to the text that impact to the reading comprehension. One of the effective strategies to help the students' reading comprehension is lexical inferencing strategy.

Lexical inferencing strategy is one of the effective strategies to guess or inference the un familiar word meaning in the text. Lexical inferencing is the most appropriate way to help students inference the unfamiliar word meaning that is needed to understand the text. This lexical inferencing strategy can be employed by inferencing the unfamiliar word meaning in the text using the context clues without depending on dictionaries. The term context clues are other words in the sentence give away or give clues to the definition of the word which help to understand the word meaning. For example, there is sometimes clue for the synonyms (words with the same meaning) or antonyms (words with the opposite meanings), or details that lead to identify the vocabulary word. This strategy also can be employed using the reader's linguistics clues, the world knowledge and also the context awareness. (Haastrup, 1991:24). The succesful students to inference the unfamiliar word meaning interpret that they can understand the word meaning, understand the text and 
use some available inferencing clues in the text. Another strategy can be used to help students understand the unfamiliar word meaning in the text that impact to the reading comprehension is lexical glossing.

Lexical glossing strategy is one of the strategy to focus on the explicit lexical items that help students to understand the unfamiliar word meaning by giving them the information of the words in the text. As Schmitt (2010:34) states that the glossing can be employed to help students understand the text well. Firstly, glossing can help students to understand the text easily. Secondly, glossing can help students to guess the unfamiliar word meaning correctly. And lastly, glossing can get students' attention to the words which help in reading process. One of the ways to use in lexical glossing by asking the students to focus on the word by colouring and underlining the words), so that the students can recognize them as chunks (Bishop, 2004). In short, If vocabulary is being glossed, it helps to make the vocabulary more salient by highlighting its form and meaning.

The studies on the use of lexical glossing and inferencing strategies actually have been more conducted by teachers and researchers since they have understood to the positive impact and the important of using the strategies for enhancing the students' vocabulary mastery and reading comprehension. Hence, the study was to find out the comparative impacts of using lexical glossing and inferencing strategies toward the students' performance in reading comprehension. The questions of this study were in the following:

1. How are the use of the lexical glossing and inferencing strategies have significantly impacted to the students reading comprehension?

2. What is the most effective strategy to use that impact to the students' success in reading comprehension?

\section{LITERATURE REVIEW}

\section{Vocabulary Mastery and Reading Comprehension}

Vocabulary mastery is needed to help the reading comprehension. Many studies have found evidence of vocabulary mastery for the reading (Paribakht \& Wesche, 1993 \& 1997). Schmitt (2001:144) states that studies on the reading implies that the vocabulary mastery can contribute to the reading understanding. As Laufer (2003) states that to achieve the comprehension, the students must have the vocabulary mastery. The vocabulary mastery can help the students to understand the text well that impact to the comprehension. The students not only need to understand directly the meaning of what they are reading, but also they need to comprehend the implied text meaning. Since the main goal of reading is comprehension. The students must have some abilities to gain the reading comprehension such as deciding the main idea of the text, making questions from the text, answering the questions about the text, employing the context clues and summarizing the text.

Besides, the students must also be involved in the reading process by using the strategies. The students must use the strategies to understand the reading text well. The strategies are used as the tool to help the students enhance the comprehension and also encounter some related problems of the text comprehension. As Barnett (1988:110) states that there were 20 effective reading strategies for understanding of unfamiliar word meaning. The students can illustrate, evaluate, inference, use some context clues to understand the text. One of the studies shows that the main role of vocabulary mastery in reading comprehension is by Nation (2001). He points out that there is a high correlation between the students' vocabulary mastery and reading comprehension. Hence, the students' vocabulary mastery is as the key factor to predict the students' ability to comprehend the reading text.

\section{Reading Strategies}

To be skilled readers, the students must have the strategies to understand the text well. The indications of the succesful students in reading are showed from the students can be more efficient to decide the unfamiliar word meaning from text because they have vocabulary mastery, experience using context clues, and greater background knowledge (Goerss et al. 1999). As an alternative strategy is often advocated by reading instructors, namely lexical glossing and inferencing strategies.

\section{Lexical Inferencing as Reading Comprehension Strategy}

Lexical inferencing is one of effective strategies to help students utilize the amount of exposure in learning vocabulary. Haastrup (1991:13) states that the inferencing process is not only guessing the unfamiliar word meaning from context but also using the students' existing knowledge like the textual context to guess the unfamiliar lexical items meaning. The way to use the inferencing strategies often needs to consider from the following two aspects. One aspect is using linguistic and other knowledge to infer the unfamiliar word meaning; the other aspect is using the cognitive processes to infer the meaning of new words. (Roskams, 2005:71). Some inferencing strategies are used in the study. Firsly, guessing the unfamiliar word meaning from the extra textual context (thematic/world knowledge). Secondly, guessing the unfamiliar word meaning from discourse context like outside the sentence in which the word occurred (using forward or backward context). Thirdly, guessing the unfamiliar word meaning from local (sentence level) context. Fourtly, guessing from association or collocation knowledge (a clue word). Fifthly, guessing from syntactic knowledge. Sixthly, guessing from visual form (similarity or morphological understanding). Sevently, guessing from phonological similarity. All these inferencing strategies are employed to understand the unfamiliar words meaning from the clues in the context to gain the reading comprehension.

\section{Lexical Glossing as Reading Comprehension Strategy}

Lexical Glossing is one strategy to focus on the explicit lexical items that help students to understand the unfamiliar word meaning by giving them the information of the words in the text. As Schmitt (2010:34) states that the lexical gloss- 
ing can be employed to help students understand the text. Firstly, glossing can help students to understand the text easily. Secondly, glossing can help students to guess the unfamiliar words meaning accurately and correctly. And lastly, glossing can get students' attention to the words which help in the reading process. One of the ways to use in lexical glossing by asking the students to focus on the word by colouring and underlining the words), so that the students can recognize them as chunks (Bishop, 2004). In other words, If vocabulary is being glossed, it helps to make the vocabulary more salient by highlighting its form.

\section{METHODS}

\section{Participants and Setting}

This study was in Potensi Utama University, Medan. The participants of this study was the Informatic engineering students of the seventh semester in 2014-2015 Academic Year. There were 60 students of 2 classes. Each of classes consists of 30 students. A test was given to 60 students to select 40 similar English proficiency level students for this study. The total number of sample was 40 students. The two classes involved that consist of 20 students then divided into first and second groups. The first group was taught using lexical glossing srategy, while the second group was treated using lexical inferencing strategy.

\section{Materials}

The materials used in this study were an assesment tests in pre-test and post-test for students' reading comprehension and vocabulary knowledge. The purpose of which was to obtain some information of students' reading comprehension, vocabulary knowledge toward text. The assesment tests consist of one reading passage with one reading comprehension questions and a test about vocabulary. The reading passage was used for the test taken from Top the TOEFL: unlocking the secrets of Ivy League students book by Leong, Kaiwen (1981). From this book was used one reading passage. The reading comprehension questions in the passage consists of 10 reading comprehension questions about the passage and 10 questions about the way to inference the unfamiliar word meaning in the passsage.

Both the first and the second groups were given Reading Comprehension materials in different methods. The students in first group were given lexical glossing strategy, while the students in second group were given and treated by lexical inferencing strategies with the help of the training materials.

\section{RESULTS AND DISCUSSION}

\section{Results}

The results were taken from the score result of study directed to the two groups separately. There were two parameters to determine the different findings from the two groups (first and second groups). Firstly, the two groups were determined and obtained from their meaningful distinction between the result scores of students in pre-tests and post-tests of the first and the second groups. Secondly, both groups were determined from their meaningful distinction between treatment directed to the two groups.

The Table 1 shows the comparison of means scores between the pre-test and the post-test for students in the first and second groups. It was determined from the different meaningful pre-test and post-test scores between students in the first group and second groups. The pre-test in first group with no glossing strategy and the pre-test in second group with no inferencing. The pre-test result showed without lexical glossing and inferencing had impacted to the students' reading comprehension. The students could'nt inference the unfamiliar word meaning and answer the reading comprehension well. And when the student were introduced to employ the lexical glossing and inferencing strategies. The students' score increased and the mistakes to answer the questions decrease. The first group was given the lexical glossing strategy, the mean result of the pre-test was 14.45 and the mean score for post-test was 16.25 . The post-test score in first group with lexical glossing strategy had showed the students were succesful to guess the unfamiliar word meaning that impact to the student's reading comprehension.

While in the second group was taught by the lexical inferencing strategy, the mean result of the pre-tests was 15.60 and the mean score for post-test was 17.35. The post-test score in second group with lexical inferencing strategy had significantly impact to the succesful students to inference the unfamiliar word meaning that impact on the students' reading comprehension. In short, the students could guess and understand the unfamiliar words meaning and answer the reading comprehension well. This result indicated that the different significant scores between the pre-tests and posttests for students in the first and second groups.

Based on the results of the post-test after treatment taught, for which evaluations were better and higher than those of the pre-test, results shows that using the lexical inferencing strategies for guessing the meaning of the text had a positive impact on results of students' vocabulary knowledge performance and reading comprehension. The mean score result of post-test in second group using lexical inferencing strategies was also higher and better than the mean score of the post-test in first group. From the result, it can be concluded that the use of lexical inferencing strategies had significantly impacted to the reading comprehension and also can be as the alternative way to enhance the reading comprehension.

\section{DISCUSSION}

The study was analyzed in the following steps. First step was the analysis of variance. For the given hypothesis, the results of analysis of variance were applied to determine any meaningful distinction between the first and second groups of the students' scores. This evaluation was conducted from the results of the pre-test and post-test.

The Table 2 shows the variance analysis and comparative scores in the Pre-test and Post-test. From this table can be seen that the standard deviation was found 2.37 for pretest in the first group. The range of the table was between 1.5 and 2.9. While the second group, the standard deviation 
Table 1. Statistics description in pre-test and post test

\begin{tabular}{llllccc}
\hline Group & Test & Mean & N & Standard Deviation & Max Score & Min Score \\
\hline First Group (No Glossing) & Pre-Test & 14.45 & 20 & 2.37 & 17 & 9 \\
Second Group (No Inferencing) & Pre Test & 15.60 & 20 & 1.93 & 1.97 & 11 \\
First Group (Glossing) & Post-Test & 16.25 & 20 & 1.77 & 20 & 15 \\
Second Group (Inferencing) & Post Test & 17.35 & 20 & 20 & 13 \\
\hline
\end{tabular}

Table 2. Variance Analysis and Pre-Test and Post-Test Scores Comparison

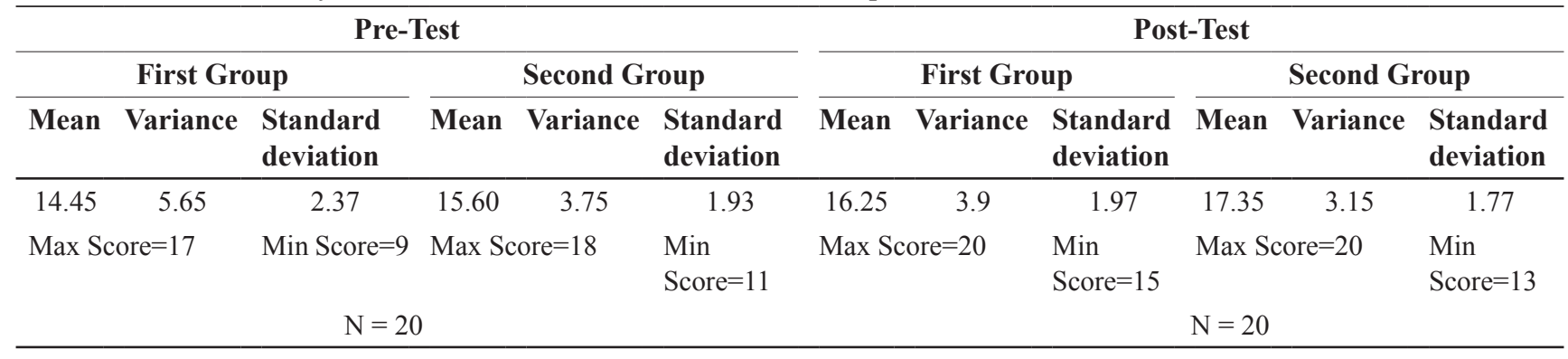

was found 1.93. The range of the table was between 1.33 and 2.66. The standard deviation for post-test in first group was found 1,97 . The range of the table was between 1.00 and 1.99. The standard deviation was found 1.77 in second group. The range of the table was between 1.33 and 2.66. It can be stated that the standard deviation for both groups in Pre-test and Post-test were correctly computed and no significant computational errors. In other words, from the different the test result scores and the range of the standard deviation of score can be stated that the use of lexical inferencing strategies had positive impact on the students' achievement on reading comprehension. In short, the comparison result of the test in the first group using the glossing strategy and in the second group using the inferencing strategy shows that the lexical inferencing strategy was the effective strategy and recomended used to enhance the students' reading comprehension.

\section{CONCLUSION}

The study implied that using the lexical inferrencing strategy significantly impact to the student's reading comprehension. The study resulted that the students' vocabulary knowledge toward the lexical inferencing strategies have impact on students' reading comprehension. In short, the succesful students to inference and understand the unfamiliar word meaning interpreted that the lower the number of unfamiliar words, the higher the available clues for the students to use to inference the correct meaning of those words so that they can understand the text well. And to face the new words they dont know in the reading text, the students can employ the inferencing strategies as the alternative way to guess the unfamiliar word meaning that help them to understand the text well.

\section{REFERENCES}

Barnett, M. A. (1988). Teaching Reading Strategies: How Methodology Affects Language Course. Foreign Language Annals, 21, No.2, pp.109-119.

Haastrup, K. (1991). Lexical Inferencing Procedures or Talking about words: Receptive Procedures in Foreign Language Learning with Special Reference to English. Tubingen, Germany: Gunter Narr.

Huckin, T. \& J. Bloch.(1993). Strategies for inferring word meaning from context: A cognitive model: In T. Huckin, M. Haynes, \& J. Coady (Eds.); Second language reading and vocabulary learning (pp.153-178). Norwood, NJ: Ablex.

Hulstijn. (1992). Retention of Inferred and Given Word Meanings: Experiments in Incidental Vocabulary Learning. In Arnaud, P. J. L. \& H. Béjoint (Eds.), Vocabulary and Applied Linguistics. Great Britain: MacMillan.

Lomicka, L.L. (1998). To Gloss or Not to Gloss: An Investigation of Reading Comprehension Online, Language Learning \& Technology, 1(2), 41-50. Retrieved from http://llt.msu.edu/vol1num2/pdf/article2.pdf.

Nation. I.S.P (2001). Learning Vocabulary in another Language. United Kingdom: Victoria University of Wellington

Paribakht, T. S. \& M. Wesche (1999). Reading and Incidental L2 Vocabulary Acquisition: An Introspective Study of Lexical Inferencing". Studies in Second Language Acquisition, 21, pp. 195-224.

Schmitt, Norbert. (2010). Reseraching Vocabulary. United Kingdom: University of Nottingham

Van Blerkom, Malcolm. (2009). Measurement and Statistics for Teachers. London: University of Pittsburgh at Johnstown 